\title{
Citation:
}

Talebpour, M.R. Sahin, O. Siems, R. and Stewart, R.A. (2014) Water and energy nexus of residential rain water tanks at an end use level: case of Australia. Energy \& Building, 80, 195-207. http://dx.doi.orq/10.1016/j.enbuild.2014.05.018

\section{Water and Energy Nexus of Residential Rain Water Tanks at an End Use Level: Case of Australia}

M.R. Talebpour*, O. Sahin*, R. Siems*, R.A. Stewart*

* Griffith School of Engineering, Griffith University, Gold Coast, Australia

\section{Corresponding author:}

Associate Professor Rodney Stewart,

Griffith School of Engineering, Gold Coast Campus, Griffith University, Parklands Drive, Southport, QLD 4222 Australia;

Phone: +61 755528778

Email: r.stewart@griffith.edu.au

\section{Highlights:}

- Energy intensity of rainwater tank end use categories empirically quantified

- Toilet cistern refills more energy intense than clothes washing or irrigation

- Toilets consumed largest total annual pump electricity in the typical home

- Low flow rate water efficient appliances adversely impacted pump energy

- Popular fixed speed pump models are inefficient at supplying indoor end uses

\begin{abstract}
Internationally, rain water tank systems have experienced a renaissance in urban areas in recent times as they are perceived to be a low cost source substitution option for many end uses or micro-components (e.g. toilet, clothes washer, irrigation, etc.) of water demand. While there are many studies that have been conducted investigating rainwater tank performance, none have explored their water-energy nexus at a micro-component level. Through a high resolution (i.e. 5 s, $0.014 \mathrm{~L} /$ pulse, $1 \mathrm{~W} /$ pulse) smart metering study, this research was able to reveal the energy intensity of three rainwater tank end uses in 19 residential homes located in Gold Coast City, Queensland, Australia. Half flush toilet cistern events were found to have the highest variability of energy intensity values between homes (1.05 to $3.32 \mathrm{Wh} / \mathrm{L})$ and also the highest energy intensity at $1.88 \mathrm{Wh} / \mathrm{L}$. Full flush toilet events had a tighter range (1.02 to $2.30 \mathrm{Wh} / \mathrm{L})$ and slightly lower energy intensity than half flush events at $1.61 \mathrm{Wh} / \mathrm{L}$. Clothes washer energy intensity values were quite variable $(0.90$ to $2.73 \mathrm{Wh} / \mathrm{L})$ but on average were lower than toilet flushing at $1.28 \mathrm{Wh} / \mathrm{L}$. Lastly, irrigation events had the tightest range (0.83 to
\end{abstract}


1.66 Wh/L) and lowest average energy intensity of $1.12 \mathrm{Wh} / \mathrm{L}$. The study has significant implications for building code specifications for internally plumbed rain tanks systems, particularly fit-for-purpose pump selection.

Key words: rain tank; water end use; water micro-component; pump energy; energy intensity; water-energy nexus

\section{Introduction}

\subsection{The water-energy nexus}

Many strategies have been adopted to enhance water and energy efficiency around the world. In many countries, water management programs have been developed to meet water shortages. There have also been many programs with a major focus on energy savings [1]. Despite these efforts, there is still a lack of integration in most water and energy programs, which in turn, has resulted in lower than expected savings due to the inefficient synergy created between the two resources [2].

There have been a number of recent efforts to explore the water-energy nexus associated with water supply, particularly energy consumption associated with centralised distribution networks in Australia and around the world. Energy is inevitably consumed at every point in the water use cycle from supply, treatment, water heating, and consumption to disposal. This recent surge in the number of investigations by water businesses and researchers is due to the rapidly increasing cost of electricity as well as the mainstream push for sustainability. For instance, the energy intensity associated with the pumping and treatment of surface water in the region of South-east Queensland (SEQ), where this rainwater tank study took place, was found to be between 0.21 and $0.67 \mathrm{kWh} / \mathrm{kL}$ [3]. At the residential level, research has included investigation into the energy consumption in heating hot water [3-5] and the effectiveness of energy efficient appliances [6-8]. Several programs have seen the introduction of alternate water sources (e.g. rain water tank, recycled water systems, etc.) in urban areas in many countries such as United Kingdom, Germany and Australia [9,10]. Despite the extensive consideration given to alternative water substitutions in urban areas, the energy intensity of alternate water strategies has typically not been considered at the point of conception and feasibility assessment [11]. Ideally, both economic and environmental factors should be considered at the same time to maximise the effectiveness of any strategy in the long term [12]. 


\subsection{Residential rain water tank systems}

Population growth, changes in rainfall patterns and behavioural changes have had a significant impact on urban water demand in Australia and around the world [13]. The increasing variability and scarcity of fresh water supplies in many parts of Australia has encouraged state authorities to develop a range of sustainable water management practices to maintain water security in urban areas [14]. In Australia, many state and local governments mandated the installation of internally plumbed rain water tanks (IPRWT). This trend has been mirrored worldwide, with rainwater tanks experiencing something of a renaissance.

Rain water tank systems have been prevalent in rural areas for many generations as a core water supply source, while recently there has been a strong uptake of these systems in urban areas as a means of supplementing pre-existing centralised water supply systems [15]. For instance, in Queensland, Australia where the study was undertaken, the government introduced the Queensland Development Code (QDC) MP 4.2, which aimed to reduce dependency on traditional mains water (i.e. the cities' supplied potable water) supply from the water grid by mandating that newly constructed residential households have a $5000 \mathrm{~L}$ rainwater tank connected to $100 \mathrm{~m}^{2}$ of roof catchment area to supply water to the cold tap of the clothes washer, toilets and two outdoor taps [16]. Internal fixtures supplied from a rain water tank have a backup supply of mains potable water using a trickle top-up or automatic switching valve system to ensure continuous supply [14]. It should be noted that the QDC MP 4.2 building code which commenced in 2007 at the height of the drought has been rescinded in 2013 due to full water supplies and pressure on the government to sell more water. This legislation is similar to policies in Germany and the United Kingdom, which have encouraged the installation of rain tanks in order to satisfy sustainability-orientated new building requirements [17].

A number of studies have previously attempted to validate the potential mains water (i.e. potable water received from city) savings achievable through plumbed rainwater tanks by using different methods such as: benchmarking the water usage in households having plumbed rainwater tanks to the corresponding regional water usage [18]; rainwater system tank modelling [19]; and paired statistical analysis using water billing data for households with and without IPRWT [20]. Other studies (Table 1), have determined the energy intensity of rainwater tank systems at an overall system level, but none have investigated energy intensity at an end-use or micro-component level (i.e. toilet, clothes washer, outdoor tap). That is, previous research has been limited to finding the total amount of energy used by an IPRWT system over a period of time, while this research also determines the energy intensity of individual rainwater usage events. 


\subsection{Reported energy intensity for residential rainwater tanks}

In the absence of gravity head, the vast majority of residential rainwater tanks require a pump to supply captured rainwater to end-uses. Pumps are predominantly energy intensive during their start-up and throughout a water use event. Moreover, the requirement for standby power is a hidden energy demand that can be considerable for some systems. The energy consumption of rainwater tank pumps is a function of the water consumption characteristics of the end uses (e.g. toilet, washing machine, and outdoor tap) they supply, pump model and power rating, and the flow impedance provided by the pipe network they operate within [21].

A variety of studies have been conducted to identify the energy intensity of IPRWT (Table 1). The studies have been divided into two categories, namely, theoretical studies (findings derived from modelled data) and empirical studies (data from field or laboratory experiments). The energy intensity performance indicator, especially when provided at the end use level, is quite good for international comparative assessments as it is not a region dependent indicator such as unit costs (i.e. $\$ / \mathrm{kL}$ ). The energy intensity derived from a particular system is related to the rain tank system configuration (i.e. some countries have header tanks in roof), pump size, water appliance efficiency, to name a few. In low density residential rain water tank installations, there are differences in configurations across the advanced economies examined but in many cases they have similar design features and pumps.

Table 1 Energy intensity for reported theoretical and empirical studies

\begin{tabular}{lcccc}
\hline Study & Method & $\begin{array}{c}\text { Sample } \\
\text { size }\end{array}$ & Pump type(s) & $\begin{array}{c}\text { Energy intensity } \\
\text { (kWh/KL) }\end{array}$ \\
\hline Beal et al. [22] & Empirical & 5 & Fixed speed & $2.0-3.9$ \\
Ferguson [23] & Empirical & 52 & Mixed* & $0.7-3.0$ \\
Hood et al. [24] & Empirical & 24 & Fixed speed & 1.4 \\
Retamal et al. [21] & Empirical & 10 & Mixed* & $0.9-2.3$ \\
Talebpour et al. [25] & Empirical & 5 & Fixed speed & $1.0-1.7$ \\
Umapathi et al. [14] & Empirical & 20 & Mixed* & $1.5-1.6$ \\
Cunio and Sproul [26] & Empirical & 2 & Mixed* & $0.1-1.7$ \\
Tjandraatmadja et al. [27] & Empirical & 3 & Fixed speed & $0.6-5.3$ \\
Chiu et al. [28] & Theoretical & NA & Fixed speed & 0.06 \\
Cunio and Sproul [26] & Theoretical & NA & Fixed speed & $0.10-0.20$ \\
Hallman et al. [29] & Theoretical & NA & Fixed speed & $0.24-0.36$ \\
Ghisi et al. [30] & Theoretical & NA & Fixed speed & 0.18 \\
Ward et al. [31] & Theoretical & NA & Fixed speed & 0.54 \\
\hline
\end{tabular}

*These studies considered both fixed and variable speed pumps. 
For the reported theoretical studies the calculated average energy intensity was $0.51 \mathrm{Wh} / \mathrm{L}$ with a wide range of values (i.e. $0.06 \mathrm{Wh} / \mathrm{L}$ to $0.54 \mathrm{Wh} / \mathrm{L}$ ). The reason for this wide range of values was the different pump configurations considered and also the different theory applied. For instance Chiu et al. [28], Hallman et al. [29] and Cunio et al. [26] considered only pump operational energy requirements to calculate energy intensity while Ward et al. [31] also considered pump start-up and stand-by power into their calculation. Moreover, the installed pump configuration considered and assumptions on their operation had a very significant impact on the calculation of energy intensity. The lowest energy intensity was calculated by Chiu et al. [28] as they considered an efficient system with one ground rainwater tank for collection and one at the roof for distribution. This configuration was optimal since it meant that the pump would work once a day to send water to the roof tank, which would then subsequently use this head (i.e. height) to supply water events throughout the day.

For the reported empirical studies the calculated average energy intensity was $1.86 \mathrm{Wh} / \mathrm{L}$. This value is over three times the average energy intensity of the theoretical studies (i.e. $0.51 \mathrm{Wh} / \mathrm{L}$ ). The significant difference between the theoretical and empirical studies provides some clues that theoretical assessments are not adequately considering the actual in-situ rain tank system configurations and their true system efficiency. For example, the theoretical pump efficiency in Chiu et al. [28] was assumed at 65\% (i.e. pump specification for optimal working) while Retemal et al. [21] reported pump efficiency values of around 35\% for the real case.

\subsection{Advent of smart metering enabling water and energy end use studies}

The advent of smart or intelligent metering technology now allows the collection of data at a resolution of a hundredth of a Litre at frequent recording intervals (e.g. 5 seconds) [32]. This frequent high resolution water flow data recording allows each and every water end use flow signature pattern (i.e. shower, toilet, clothes washer, etc.) to be categorised using semi-automated disaggregation approaches [33, 34] and even automated end use disaggregation [35,36]. Water end use analysis studies of residential homes supplied with centralised water has been completed internationally [37] and in Australia [38-41]. More recently homes supplied with alternate water supply sources, such as dual reticulated systems, have also been analysed [42]. This novel study paired high resolution water and electricity metering technologies, to allow a combined analysis of water and electricity consumption from IPRWT on an event by event basis, and is the first known comprehensive study to do so. 


\section{$2 \quad$ Research objectives and method}

\section{$2.1 \quad$ Objectives}

The goal of this study was to gain an in-depth understanding on the water and energy requirements of rain tank supplied end uses (e.g. toilet, clothes washer and irrigation end uses) in residential households. To achieve this goal, the following research objectives were formulated for the purpose of the study:

1. Determine the aligned water and energy consumption requirements for a number of toilet, clothes washer and irrigation events supplied by the IPRWT system for a sample of instrumented residential households;

2. Compare the energy intensity values for the four IPRWT supplied end use categories;

3. Compare the sampled energy intensity values within each water end use category; and

4. Compare theoretical with actual energy intensity values.

\section{$2.2 \quad$ Method overview}

A mixed method research approach was followed to collect information regarding the water and energy consumption of individual water end use events as well as some demographic data on each of the 19 monitored households. This process resulted in a total of 380 discrete events for each of the four end use categories (i.e. half flush cistern, full flush cistern, clothes washer and irrigation). Measurement of water and energy usage occurred via installed smart meters with subsequent remote transfer of high resolution data to a storage server housed at the University. Information about each sampled household occurred through a demographic and water-energy appliance stock survey. Further description of the different elements of experimental design and research methods are described below.

\subsection{Experimental design for IPRWT water and energy end use measurement}

Modified water meters were installed before and after the automatic rainwater tank switch to capture the amount of water that was supplied by both mains water (i.e. centralised water supply) and tank water. These smart meters measure flow to a resolution of 72 pulses/L or a pulse every $0.014 \mathrm{~L}$. The smart meters were connected to data loggers with a storage capacity of 2 million readings. The loggers were programmed to record pulse counts at five seconds intervals. A high resolution electricity meter $(0.1 \mathrm{Wh} / \mathrm{pulse})$ was installed along with the smart water meters and data logger in order to collect a high resolution record of energy ( $0.1 \mathrm{Wh}$ per pulse) at the same time of recording high resolution water end use consumption. A critical requirement of this study was that water and energy usage was recorded concurrently and at the same intervals by the data logger in 
order to determine the energy intensity of each individual water end use event occurring in each residential household in the study. Figure 1 illustrates the experimental design for IPRWT water and energy end use measurement. The data loggers, electricity meters and water meters utilised in this study comply with Australian Standards and were subject to testing prior to delivery. Before field deployment they were further tested in a laboratory environment by running a number of water and energy use events and comparing actual and recorded accuracy. Field accuracy was also checked by running a number of water end use events and comparing measured consumption (i.e. toilet cistern volume) with that recorded by the meters. This quality assurance process provided the research team with the necessary confidence to complete the subsequent data analysis on the collected sample.

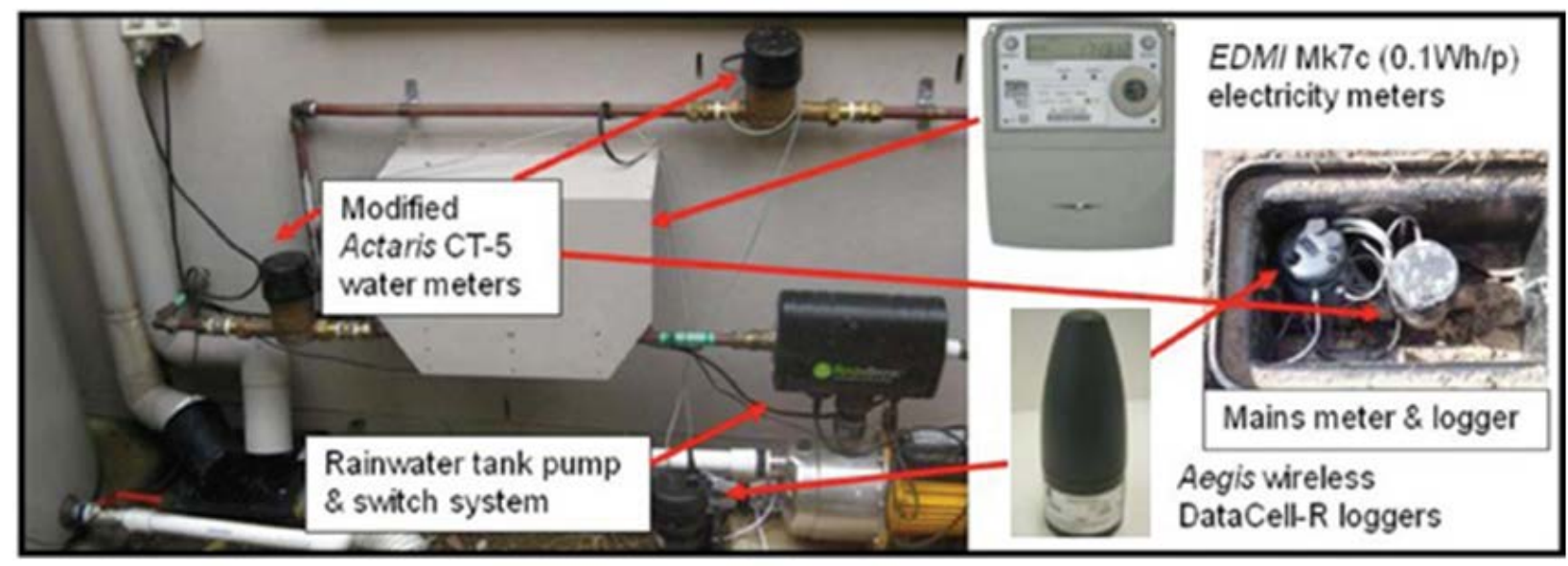

Fig. 1. Water and energy end use measurement design

\subsection{Sample selection process}

Approximately 14,000 households with the government mandated IPRWT have been constructed in the period from 2007 to 2012 in Gold Coast City, Australia [43]. Over 2,000 households were targeted to participate in the study through a range of recruitment initiatives including mailed and emailed packages and door knocking. Fifty households indicated consent to participate in this study. After a site inspection and audit of consenting households, a total of 19 were selected to participate in the study. All recruited households contained IPRWT with fixed speed pumps and an automatic switch system; which was found to be the overwhelmingly popular configuration. 


\subsection{Description of study sample}

Table 2 provides a brief description of some key features of the study sample. It should be noted that the experimental setup for each household was costly at approximately AUD $\$ 4,000$, which constrained the size of the sample. The average number of people per household was 3.10 people for the entire sample with $26 \%$ of households having more than one child. The total number of people in the sample was 59 with $37 \%$ of households being occupied by two or less people. Lot sizes ranged from 500-1,000+ $\mathrm{m}^{2}$ and all sampled households had some garden or grassed area.

Table 2 Summary of key descriptive data for sampled households

\begin{tabular}{cccccc}
\hline $\begin{array}{c}\text { Home } \\
\text { ID }\end{array}$ & \multicolumn{2}{c}{ Number of occupants } & Total land & Pump input \\
Total & Adults & Children & Size $\left.\mathbf{( m}^{\mathbf{2}}\right)$ & (W) \\
\hline RW01 & 3 & 2 & 1 & $701-1000$ & 770 \\
RW04 & 2 & 2 & 0 & $501-700$ & 770 \\
RW05 & 6 & 2 & 4 & $1000+$ & Unknown \\
RW06 & 1 & 1 & 0 & $501-700$ & 770 \\
RW07 & 2 & 2 & 0 & $501-700$ & 770 \\
RW08 & 4 & 2 & 2 & $1000+$ & 720 \\
RW11 & 2 & 2 & 0 & $701-1000$ & Unknown \\
RW12 & 4 & 3 & 1 & $1000+$ & 1170 \\
RW13 & 2 & 2 & 0 & $501-700$ & 770 \\
RW14 & 5 & 2 & 3 & $701-1000$ & 770 \\
RW16 & 2 & 2 & 0 & $701-1000$ & 770 \\
RW18 & 3 & 2 & 1 & $501-700$ & 770 \\
RW19 & 4 & 2 & 2 & $701-1000$ & 720 \\
RW20 & 2 & 2 & 0 & $501-700$ & 770 \\
RW22 & 3 & 2 & 1 & $501-700$ & 770 \\
RW23 & 3 & 2 & 1 & $501-700$ & 770 \\
RW24 & 4 & 2 & 2 & $501-700$ & 770 \\
RW26 & 4 & 4 & 0 & $501-700$ & 770 \\
RW28 & 3 & 2 & 1 & $701-1000$ & 770 \\
\hline
\end{tabular}

\subsection{Data collection and storage}

The data loggers employed were capable of two way communication over GPRS networks, allowing the collected data to be transmitted via email to a Griffith University database. Removable SIM cards were affixed into each logger and tested prior to installation in the field. The frequency of transfer was daily. In some cases, the interval of sending data was reduced to every 6 hours due to poor GPRS signal at the location. A File Transfer Protocol (FTP) server was established to allow researchers communicate with loggers remotely. Raw data files, in the ASCII format, were then modified into .txt files to allow trace flow analysis. 
Griffith University’s Smart Meter Information Portal (SMIP) was developed, which autonomously modified the raw ASCII files into .txt files and also allowed users to select parcels of water or energy data for a particular period of time for a particular selection of households (i.e. query system built).

\subsection{Data processing procedures}

After data preparation, files were repaired for any discontinuities using MATLAB scripts [44] (resulting from logger maintenance and battery failure) and subject to trace analysis. Trace analysis is essentially the disaggregation of usage information present in a data feed into classified end-use events. The software employed to carry out this task was Trace Wizard [45]. The program gives a visualisation of a data feed and allows the creation of water end use event pattern recognition templates. These user created templates contain the characteristics that differentiate one end-use from another (i.e. duration, flow rate etc.). After a template is created the program classifies all consumption data in a file based on these characteristics. A time-consuming iterative process is required to achieve high accuracy.

For a detailed discussion on the trace analysis process, readers are referred to existing published literature [34 46]. Data for 6 months from October 2012 to March 2013 was analysed, with 20 events classified from each end-use from each participating household. This process resulted in a total of 1,210 water end use samples being utilised for the results section presented later.

The stock and appliance surveys hastened the process and improved the classification accuracy of water flow trace analysis into discrete water end use events. It is acknowledged that water end use classification using trace wizard is not $100 \%$ accurate for the seven different end uses disaggregated from the flow data (i.e. half flush cistern, full flush cistern, dishwasher, clothes washer, bathtub, shower and irrigation), however the experimental arrangement utilised in this study and the focus on a limited number of IPRWT supplied mechanised end uses (i.e. half flush cistern, full flush cistern, clothes washer and irrigation) has produced reliable accuracy [25]. Reliable classification accuracy was achievable due to the installation of three water meters which significantly improved event recognition processes. To illustrate, an event may be mains supplied to a non-mandated end-use, mains supplied to a mandated end-use, tank supplied to a mandated end-use, or a combination of tank and mains supply to a mandated end-use (particularly common with clothes washer events). 
With just one data stream an analyst would be completely reliant on the event characteristics to classify the end-use, but given that three data streams were available at three locations, the supply source and event category was clearly identifiable. Having three meters was particularly advantageous for categorising simultaneous events (e.g. toilet and tap event occurring simultaneously). Once a trace analysis was complete for each household, a database file compatible with Access ${ }^{\mathrm{TM}}$ was created. This facilitated easy transfer to the statistical analysis program utilised (i.e. SPSS).

\section{$3 \quad$ Data analysis and results}

\subsection{Determining the energy intensity of individual events}

Analysis begins at an individual event level. Depending on the supply source, the logger feeds will display differently. For example, if the RWT plumbed end use is supplied by mains water, the same flow trace will appear on both the front of house meter as well as both meters located before and after the switch system. Otherwise, a flow event pattern supplied by the rain tank only appears for the meter after the switch system. When an event is partially or wholly rainwater supplied, pump energy consumption is evident from the electricity meter. Figure 2 illustrates energy intensity mapping examples for a half flush event (a), clothes washer event (b) and irrigation event (c). Half flush events are recognised as generally having the highest energy intensity among the IPRWT supplied end use events. High energy intensity for a half flush event is evident in Figure 2 (a) due to the short duration of the event and low average flow rate for the event (e.g. $6 \mathrm{~L} / \mathrm{min}$ ). The illustrated half flush toilet event used 4.2 L from the RWT and 6.3Wh from the RWT pump, which equates to an energy intensity for this event of $1.5 \mathrm{Wh} / \mathrm{L}$. The sample clothes washer event shown exhibits periodic water (and thus electricity) consumption, which corresponds to the wash and rinse cycles. The events total duration was 25 minutes, with $107 \mathrm{~L}$ of water supplied using $105 \mathrm{Wh}$, providing an energy intensity of $0.98 \mathrm{Wh} / \mathrm{L}$. The irrigation sample event shown is a steady garden watering event of approximately 40 minutes duration. The flow rate and electricity demand remain at a constant ratio throughout the event, with $410 \mathrm{~L}$ supplied for the use of $386 \mathrm{Wh}$, making it the most efficient of the three sampled events at $0.94 \mathrm{Wh} / \mathrm{L}$. 


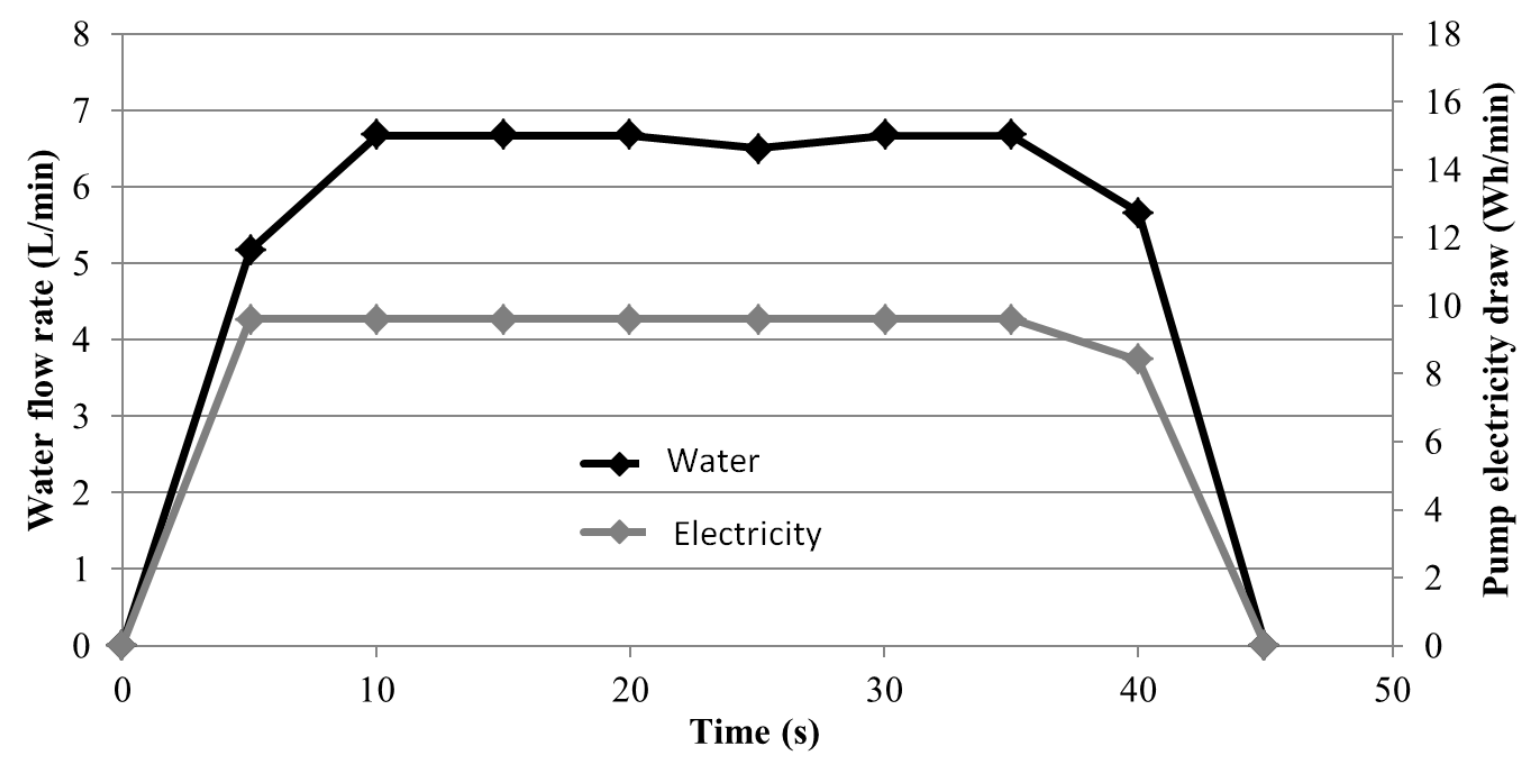

(a) Half flush toilet event

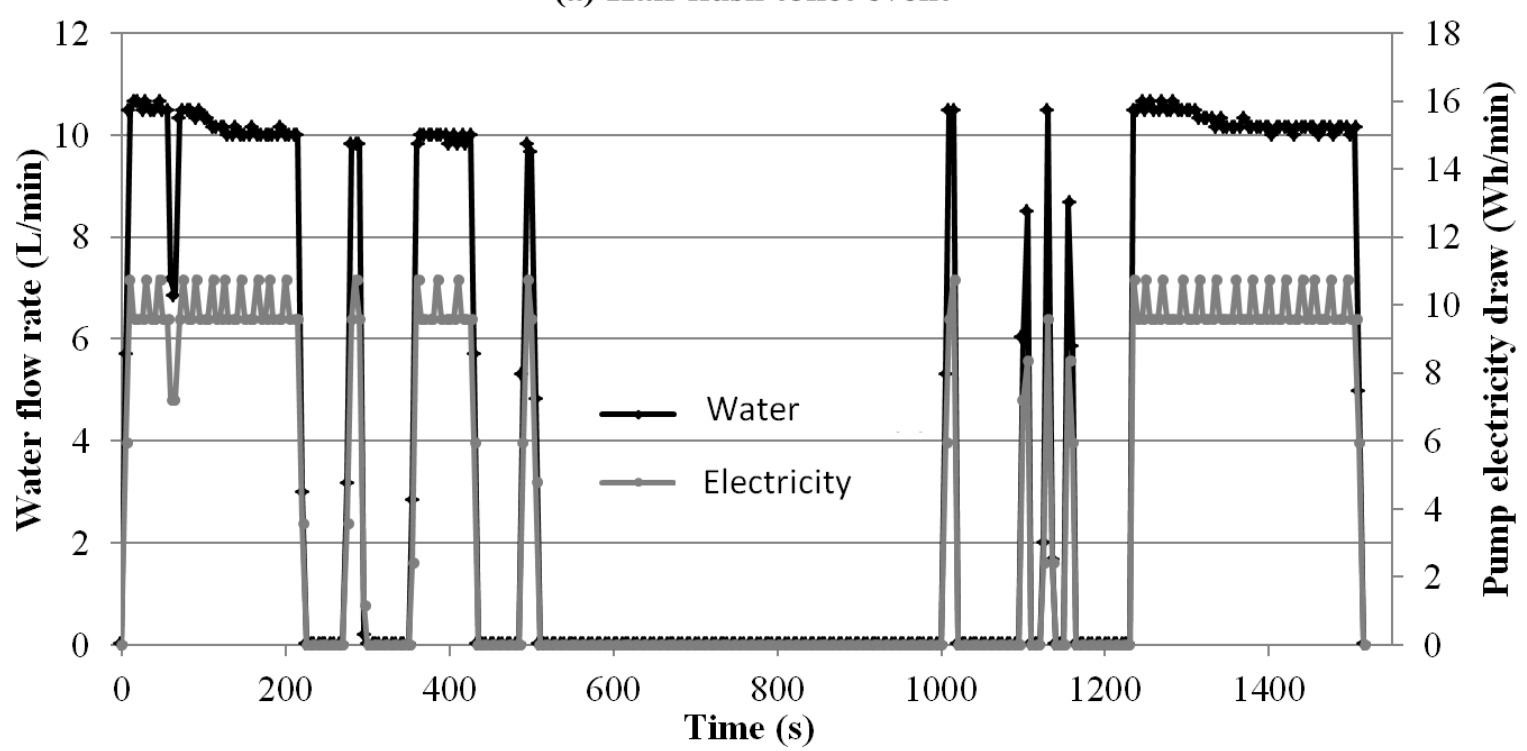

(b) Clothes washer event

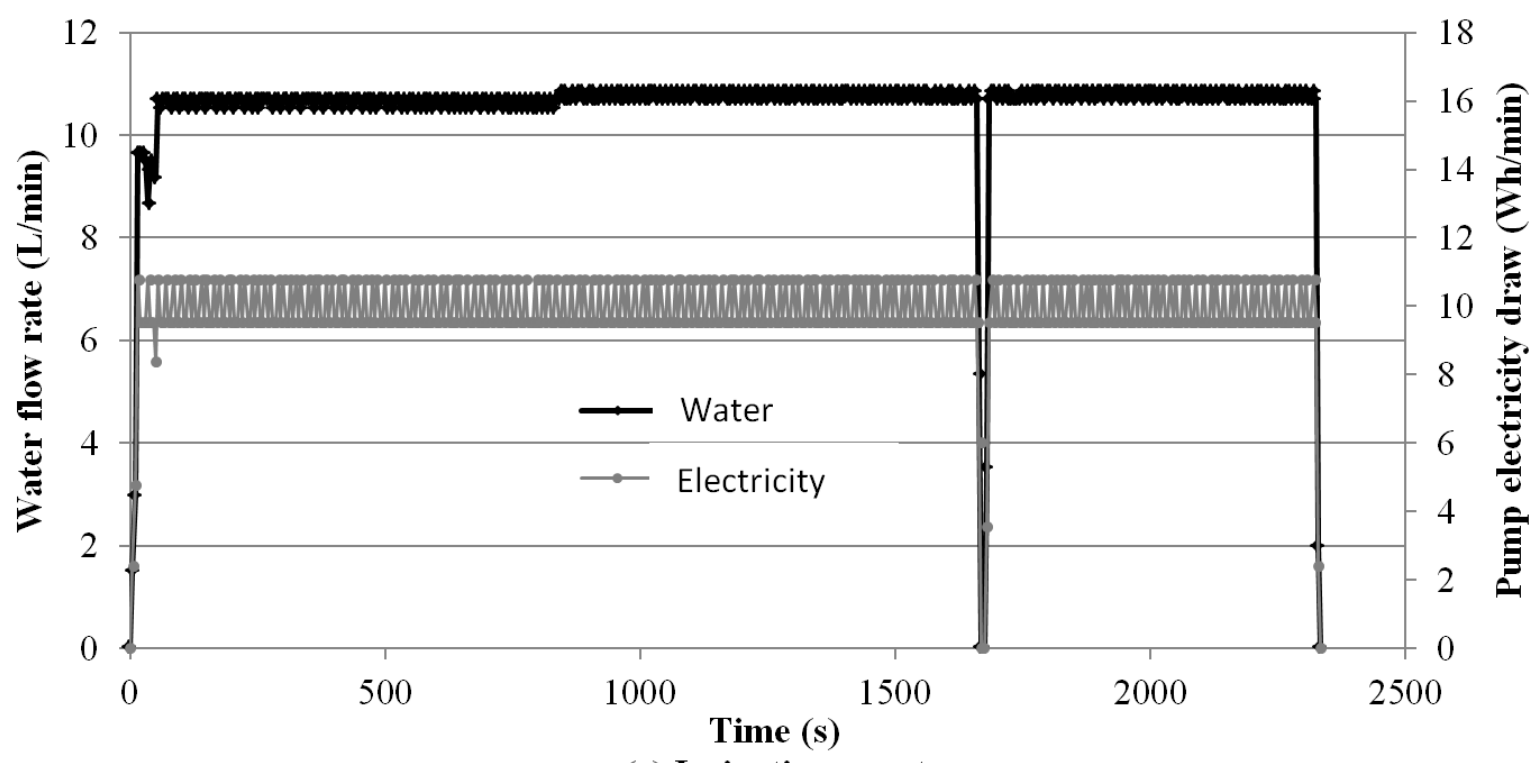

(c) Irrigation event

Fig. 2. Example of water and electricity usage for three IPRWT supplied end-use categories 


\subsection{Sampling the energy intensity of different end uses for individual homes}

As described in the methods section of the paper, to obtain representative average energy intensity values for each end use category as well as to gauge the degree of variability in events (i.e. duration, flow rates, energy draw rates, etc.), a total of 20 end use events were analysed for each category in each of the sampled homes. A total of 1,210 end use samples were analysed. The complete listing of results for a few individual households is presented to demonstrate the analysis process. One of the sampled homes, RW05, had 6 occupants, large land size (+1000 $\mathrm{m}^{2}$ ), and a submersible pump with automatic switch (Figure 3). The clothes washer end use category was found to have the highest energy intensity in this home with an average of $1.70 \mathrm{Wh} / \mathrm{L}$ and standard deviation of $0.03 \mathrm{Wh} / \mathrm{L}$ between captured events, followed by the half flush toilet end use category at $1.58 \mathrm{Wh} / \mathrm{L}$ $(\mathrm{SD}=0.09 \mathrm{Wh} / \mathrm{L})$ and full flush toilet end use category at $1.38 \mathrm{Wh} / \mathrm{L}(\mathrm{SD}=0.04 \mathrm{Wh} / \mathrm{L})$.

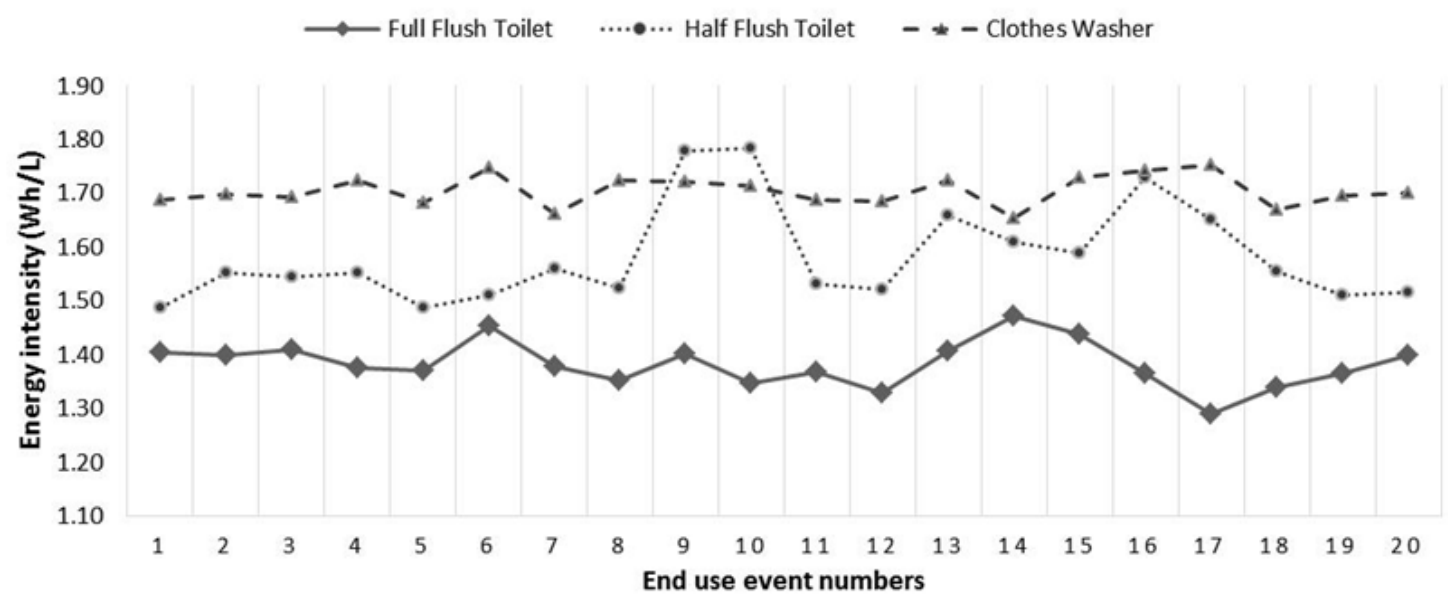

Fig. 3. End use events energy intensity values for individual home (Home ID: RW05)

This particular home did not irrigate at any stage during the study period which is not uncommon for many households located in Gold Coast City [47]. Typically, the highest energy intensity comes from the half flush toilet end use category. However, in this particular home the clothes washer had the highest energy intensity due its wash cycle characteristics. The RW05 clothes washer is a modern $7 \mathrm{~kg}$ front loader clothes washer with more than 10 wash cycles (i.e. much more shorter intense cycles than traditional top loader clothes washers), and consumed a low 43 litres per wash (under the selected wash cycles) on average. 
Table 3 shows 20 different events for the half flush toilet end use category for household RW05,

highlighting the degree of variation in energy intensity for this end use category in this particular household.

The water consumption range for the half flush toilet in this home was high at between 3.53 and $5.23 \mathrm{~L}$, with a mean value of 4.30 L (SD = 0.47 L ). Events 9, 10 and 16 were the lowest volume half flush events (i.e. volume $<4$ L) and had the highest energy intensity. Very low event volumes correspond with a much higher proportion of the duration being devoted to the energy intensive start-up and wind-down phases of the pumping cycle.

Table 3 Twenty sampled half flush toilet events for home RW05

\begin{tabular}{lccccccc}
\hline $\begin{array}{l}\text { Event } \\
\text { No. }\end{array}$ & $\begin{array}{c}\text { Volume } \\
\text { (L) }\end{array}$ & $\begin{array}{c}\text { Electricity } \\
\text { draw } \\
\text { (Wh) }\end{array}$ & $\begin{array}{c}\text { Duration } \\
\mathbf{( s )}\end{array}$ & $\begin{array}{c}\text { Peak } \\
\text { draw } \\
\text { (Wh/min) }\end{array}$ & $\begin{array}{c}\text { Average } \\
\text { draw } \\
\text { (Wh/min) }\end{array}$ & $\begin{array}{c}\text { Peak } \\
\text { flow rate } \\
\text { (L/min) }\end{array}$ & $\begin{array}{c}\text { Average } \\
\text { flow rate } \\
\text { (L/min) }\end{array}$ \\
\hline $\mathbf{1}$ & 4.98 & 7.40 & 55 & 9.60 & 8.07 & 8.17 & 5.78 \\
$\mathbf{2}$ & 4.06 & 6.30 & 50 & 9.60 & 7.56 & 8.17 & 5.14 \\
$\mathbf{3}$ & 4.34 & 6.70 & 50 & 9.60 & 8.04 & 8.17 & 5.67 \\
$\mathbf{4}$ & 4.06 & 6.30 & 45 & 9.60 & 8.40 & 8.17 & 5.71 \\
$\mathbf{5}$ & 4.17 & 6.20 & 50 & 9.60 & 7.44 & 8.17 & 5.09 \\
$\mathbf{6}$ & 4.17 & 6.30 & 50 & 9.60 & 7.56 & 8.17 & 5.15 \\
$\mathbf{7}$ & 4.93 & 7.70 & 55 & 9.60 & 8.40 & 8.17 & 5.73 \\
$\mathbf{8}$ & 4.73 & 7.20 & 55 & 9.60 & 7.85 & 8.17 & 5.32 \\
$\mathbf{9}$ & 3.54 & 6.30 & 45 & 9.60 & 8.40 & 8.17 & 5.62 \\
$\mathbf{1 0}$ & 3.53 & 6.30 & 45 & 9.60 & 8.40 & 8.17 & 5.60 \\
$\mathbf{1 1}$ & 5.23 & 8.00 & 55 & 9.60 & 8.73 & 8.17 & 6.35 \\
$\mathbf{1 2}$ & 4.21 & 6.40 & 50 & 9.60 & 7.68 & 8.17 & 5.09 \\
$\mathbf{1 3}$ & 4.64 & 7.70 & 50 & 9.60 & 9.24 & 8.17 & 6.39 \\
$\mathbf{1 4}$ & 4.48 & 7.20 & 50 & 9.60 & 8.64 & 8.17 & 5.99 \\
$\mathbf{1 5}$ & 4.03 & 6.40 & 45 & 9.60 & 8.53 & 8.01 & 5.69 \\
$\mathbf{1 6}$ & 3.53 & 6.10 & 45 & 9.60 & 8.13 & 8.01 & 5.60 \\
$\mathbf{1 7}$ & 4.24 & 7.00 & 50 & 9.60 & 8.40 & 8.17 & 5.79 \\
$\mathbf{1 8}$ & 4.18 & 6.50 & 50 & 9.60 & 7.80 & 8.17 & 5.27 \\
$\mathbf{1 9}$ & 4.84 & 7.30 & 55 & 9.60 & 7.96 & 8.01 & 5.57 \\
$\mathbf{2 0}$ & 4.23 & 6.40 & 50 & 9.60 & 7.68 & 8.17 & 5.14 \\
\hline
\end{tabular}

Now examining another home (RW23), which had 3 occupants, a large clothes washer (7+ kg load capacity), and a $770 \mathrm{~W}$ fixed speed pump with automatic switch system. As shown in Figure 4, 20 sampled events were obtained for all end use categories except irrigation, where only 10 samples occurred during the study period since this home rarely irrigated. The half flush toilet end use category had the highest energy intensity of 1.84 Wh/L (SD = 0.06 Wh/L), followed by the full flush toilet, clothes washer and irrigation categories with an energy intensity of $1.57 \mathrm{Wh} / \mathrm{L}(\mathrm{SD}=0.07 \mathrm{Wh} / \mathrm{L}), 1.26 \mathrm{Wh} / \mathrm{L}(\mathrm{SD}=0.05 \mathrm{Wh} / \mathrm{L})$ and 1.07 Wh/L (SD = 0.31 Wh/L), respectively. The clothes washer in this home was a large front loader model which had lower energy intensity than most of the other smaller front loader clothes washers in this study. 
For another household (RW24), with similar fixtures to RW23, the half flush toilet event category had the highest energy intensity at $2.28 \mathrm{Wh} / \mathrm{L}(\mathrm{SD}=0.12 \mathrm{Wh} / \mathrm{L})$ and irrigation events had the lowest at $1.28 \mathrm{Wh} / \mathrm{L}(\mathrm{SD}$ $=0.34 \mathrm{Wh} / \mathrm{L}$ ). Figure 5 illustrates the variability in irrigation event energy intensities when compared to the more consistent 'mechanised' end use categories. Irrigation events had variable water flow rates and durations resulting in them having a higher variation in energy intensity. Clothes washer events were found to be the second most variable for the majority of sampled homes, due largely to the numerous washing cycle options available for modern clothes washers (Figure 5).

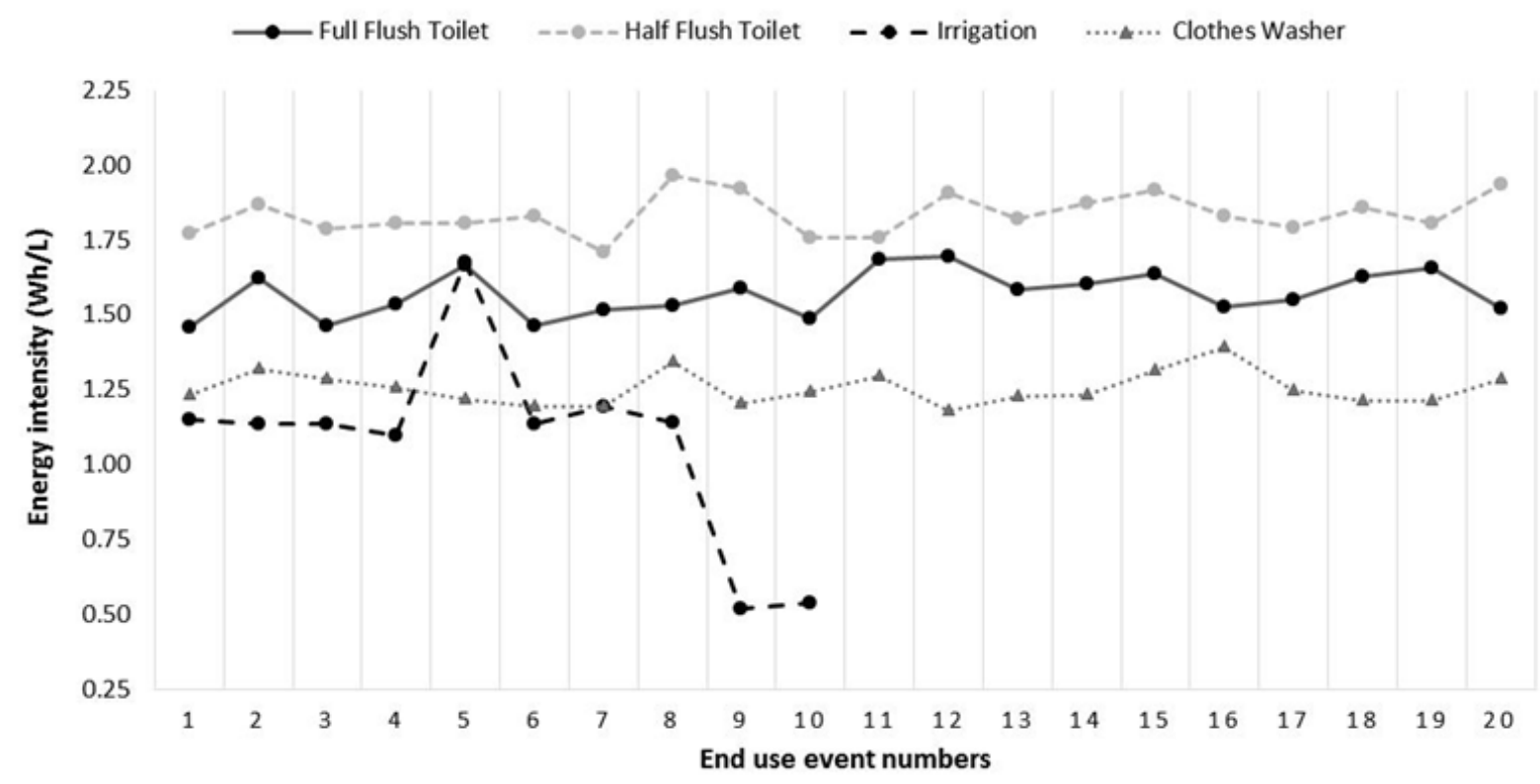

Fig. 4. Energy intensity for sampled events in the four IPRWT supplied end use categories in Home RW23

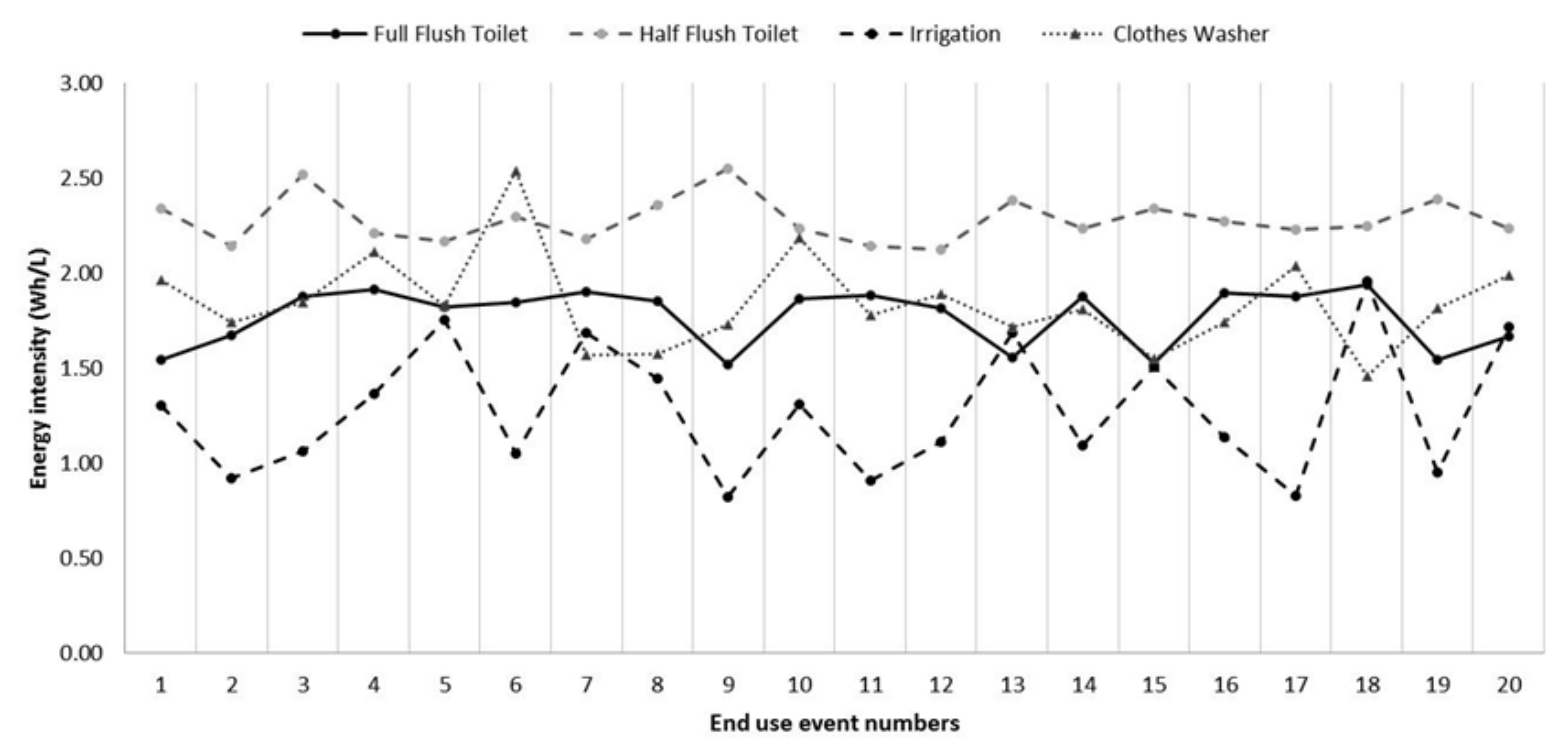

Fig. 5. Energy intensity for sampled events in the four IPRWT supplied end use categories in Home RW24 


\subsection{Energy intensity for the complete sample}

\subsubsection{Half flush toilet end use category}

A total of 380 events were analysed for the half flush toilet end use category for the 19 recruited households. From within this 380 half flush toilet event sample, the energy intensity for this category ranged from $0.96 \mathrm{Wh} / \mathrm{L}$ to $3.65 \mathrm{Wh} / \mathrm{L}$. The average energy intensity for the sample was $1.88 \mathrm{Wh} / \mathrm{L}$ with a standard deviation of $0.53 \mathrm{Wh} / \mathrm{L}$. As presented in Table 4, RW06 and RW08 had the lowest and highest energy intensity in the sample, respectively.

Table 4 Half flush toilet end use category descriptive data

\begin{tabular}{ccccc}
\hline Home ID & $\begin{array}{c}\text { Average tank } \\
\text { water } \\
\text { consumption } \\
\text { (L) }\end{array}$ & $\begin{array}{c}\text { Average } \\
\text { electricity } \\
\text { consumption } \\
\text { (Wh) }\end{array}$ & $\begin{array}{c}\text { Average } \\
\text { duration } \\
\text { (s) }\end{array}$ & $\begin{array}{c}\text { Average } \\
\text { energy } \\
\text { intensity } \\
\text { (Wh/L) }\end{array}$ \\
\hline RW01 & 2.16 & 4.56 & 50.00 & 2.11 \\
RW04 & 4.44 & 6.61 & 44.25 & 1.49 \\
RW05 & 4.31 & 6.79 & 50.00 & 1.58 \\
RW06 & 4.02 & 4.24 & 30.00 & 1.05 \\
RW07 & 3.21 & 7.84 & 59.00 & 2.44 \\
RW08 & 2.67 & 7.40 & 44.75 & 2.77 \\
RW11 & 2.27 & 4.63 & 41.00 & 2.04 \\
RW12 & 3.35 & 6.26 & 35.75 & 1.86 \\
RW13 & 2.23 & 3.91 & 32.50 & 1.75 \\
RW14 & 4.17 & 6.31 & 45.75 & 1.51 \\
RW16 & 3.18 & 4.81 & 36.50 & 1.51 \\
RW18 & 3.49 & 5.95 & 37.75 & 1.70 \\
RW19 & 2.80 & 4.99 & 32.50 & 1.78 \\
RW20 & 1.83 & 6.07 & 98.50 & 3.32 \\
RW22 & 4.23 & 5.59 & 40.75 & 1.32 \\
RW23 & 4.64 & 8.51 & 74.00 & 1.84 \\
RW24 & 2.63 & 5.97 & 118.00 & 2.27 \\
RW26 & 3.19 & 5.75 & 43.50 & 1.80 \\
RW28 & 2.33 & 3.80 & 32.50 & 1.63 \\
\hline Average & 3.22 & 5.79 & 49.84 & 1.88 \\
SD & 0.88 & 1.31 & 23.30 & 0.53 \\
\hline
\end{tabular}

The low $1.05 \mathrm{Wh} / \mathrm{L}$ energy intensity for RW06 is derived from the high flow rate to fill the comparatively high volume of the half flush events in this home. Put simply, the pump operates at a relatively high capacity for a short 30 second period. In contrast, the $3.33 \mathrm{Wh} / \mathrm{L}$ average for home RW20 was due to the low volume and low flow cistern filling rate of its half flush events. The total energy intensity of a pump is a function of the pump start-up energy usage, energy used during the pump operation, and the water consumed by the end use. Thus, in the case of homes RW06 and RW20, since the pump start-up energy requirements were the same in 
both homes, the water consumption and the duration of the pump operation were the defining factors in determining the energy intensity. For RW20, the location of the toilet was on the second floor of the dwelling, which contributed to a situation where the pump needed to operate for nearly 100 seconds to fill just $1.8 \mathrm{~L}$ (i.e. very low flow rate meant a poor pump efficiency), thereby resulting in a very high energy intensity for this end use category. The large difference between the energy intensity values for these two homes demonstrates that many toilet cisterns are poorly configured for use with a RWT system containing a fixed speed pump, with pump energy intensities approaching levels required for reverse osmosis seawater desalination [48]. As seen with RW20, a water efficient toilet cistern (low fill volume) can be at odds with energy efficiency. This could be rectified by increasing the fill rate of the cistern, without adjusting the total volume of water per fill. This would see the pump operate for a shorter period of time and closer to its optimal pumping capacity.

\subsubsection{Full flush toilet end use category}

As per half flush events, 20 full flush events were analysed from each of the 19 homes to create a 380 event sample (Table 5). The average energy intensity for the whole sample was $1.61 \mathrm{Wh} / \mathrm{L}$ (considered as total energy over total water supplied for the whole sample) and the standard deviation was $0.37 \mathrm{Wh} / \mathrm{L}$. Full flush events were found to have a tighter energy intensity range than half flush events (i.e. $0.97 \mathrm{Wh} / \mathrm{L}$ to $2.68 \mathrm{Wh} / \mathrm{L}$ ) among 380 events. This tighter range and the lower average energy intensity are a result of the larger fill volumes. RW06 also had the one of the lowest energy intensity values, with a fast fill time (50s) and a large cistern fill volume of 7.5 L. The home with the highest energy intensity for full flush events was RW18. This was due primarily to the low flow rate of cistern refill for the low $3.0 \mathrm{~L}$ volume.

Again, the most water efficient fixture is shown to have one of the highest energy intensities. This study provides evidence that there was little consideration given for the selection of the most effective pump for a particular household's IPRWT supplied appliance stock. 
Table 5 Full flush toilet end use category descriptive data

\begin{tabular}{lcccc}
\hline Home ID & $\begin{array}{c}\text { Average } \\
\text { tank water } \\
\text { consumption } \\
\text { (L) }\end{array}$ & $\begin{array}{c}\text { Average } \\
\text { electricity } \\
\text { consumption } \\
\text { (Wh) }\end{array}$ & $\begin{array}{c}\text { Average } \\
\text { duration } \\
\text { (s) }\end{array}$ & $\begin{array}{c}\text { Average } \\
\text { energy } \\
\text { intensity } \\
\text { (Wh/L) }\end{array}$ \\
\hline RW01 & 4.49 & 7.03 & 73.25 & 1.56 \\
RW04 & 6.57 & 9.91 & 65.00 & 1.51 \\
RW05 & 7.77 & 10.73 & 76.25 & 1.38 \\
RW06 & 7.48 & 7.64 & 50.50 & 1.02 \\
RW07 & 5.33 & 10.03 & 61.75 & 1.88 \\
RW08 & 3.85 & 8.85 & 54.00 & 2.30 \\
RW11 & 6.86 & 9.29 & 69.75 & 1.35 \\
RW12 & 6.69 & 11.21 & 59.75 & 1.68 \\
RW13 & 5.02 & 7.47 & 55.50 & 1.49 \\
RW14 & 6.69 & 9.49 & 67.50 & 1.42 \\
RW16 & 5.43 & 7.39 & 52.50 & 1.36 \\
RW19 & 4.55 & 6.57 & 40.50 & 1.44 \\
RW20 & 4.75 & 10.58 & 123.25 & 2.22 \\
RW22 & 6.90 & 8.64 & 60.75 & 1.25 \\
RW23 & 6.90 & 10.80 & 91.50 & 1.56 \\
RW24 & 5.24 & 9.16 & 150.25 & 1.75 \\
RW26 & 6.48 & 10.62 & 75.75 & 1.64 \\
RW28 & 6.88 & 9.60 & 65.50 & 1.40 \\
\hline Average & 5.84 & 9.06 & 70.97 & 1.61 \\
SD & 1.32 & 1.47 & 26.20 & 0.37 \\
\hline
\end{tabular}

\subsubsection{Clothes washer end use category}

Capturing and analysing clothes washer events were significantly more complex than cistern flush end uses, due to their many different usage permutations. These appliances are generally installed to draw water from both hot and cold connections, with only the cold connection connected to the IPRWT. Hence, events may be composed of entirely non-supplied hot-water, entirely IPRWT sourced cold water, or a combination of the two, depending on user cycle selection. This results in significant variability between events in the same home, and between homes. 14 of the 19 households were found to use at least partial cold water washes, with the remaining households preferring hot only washes or hand washing. 282 clothes washer events were captured across the 14 useable homes.

The energy intensity of clothes washer events ranged from $0.87 \mathrm{Wh} / \mathrm{L}$ to $2.98 \mathrm{Wh} / \mathrm{L}$ (Table 6). Some homes selected an identical wash cycle throughout the study period, resulting in standard deviations as low as 0.01 Wh/L across the events captured for RW22. Other homes varied their wash cycle across the captured events. When this change in washing cycle selection, led to significant changes in the individual cycles flow rate, the standard deviation rose as high as $0.25 \mathrm{Wh} / \mathrm{L}$. 
Table 6 Clothes washer end use category descriptive data

\begin{tabular}{lcccc}
\hline Home ID & $\begin{array}{c}\text { Average } \\
\text { tank water } \\
\text { consumption } \\
\text { (L) }\end{array}$ & $\begin{array}{c}\text { Average } \\
\text { electricity } \\
\text { consumption } \\
\text { (Wh) }\end{array}$ & $\begin{array}{c}\text { Average } \\
\text { duration } \\
\text { (s) }\end{array}$ & $\begin{array}{c}\text { Average } \\
\text { energy } \\
\text { intensity } \\
\text { (Wh/L) }\end{array}$ \\
\hline RW04 & 94.43 & 94.15 & 1410.75 & 1.00 \\
RW07 & 155.83 & 157.00 & 2189.50 & 1.01 \\
RW11 & 48.19 & 66.04 & 4235.50 & 1.37 \\
RW12 & 35.24 & 57.54 & 1271.50 & 1.63 \\
RW13 & 43.02 & 56.30 & 2823.75 & 1.31 \\
RW14 & 54.41 & 148.32 & 1945.25 & 2.73 \\
RW16 & 70.31 & 91.99 & 6797.50 & 1.31 \\
RW18 & 51.90 & 46.85 & 642.00 & 0.90 \\
RW19 & 126.67 & 125.74 & 2074.00 & 0.99 \\
RW20 & 70.93 & 71.26 & 1058.25 & 1.00 \\
RW22 & 43.62 & 49.69 & 1565.75 & 1.14 \\
RW23 & 91.95 & 114.74 & 6039.50 & 1.25 \\
RW26 & 108.97 & 129.87 & 2276.00 & 1.19 \\
RW28 & 43.02 & 45.42 & 4135.75 & 1.06 \\
\hline Average & 74.18 & 89.63 & 2747.50 & 1.28 \\
SD & 36.52 & 39.20 & 1874.25 & 0.46 \\
\hline
\end{tabular}

The homes found to have the lowest energy intensities were those where the clothes washer would draw a large volume of water in a short period, such as RW04 and RW07. The average durations shown in Table 6 represent the length of time between the first and last rainwater usage for an event. However, for some of the washing and rinse cycles, there are long periods for most events where no water is supplied and the pump is inactive. The home with the highest energy intensity (i.e. RW14 with $2.73 \mathrm{Wh} / \mathrm{L}$ ) had a clothes washer which required a small flow rate of water almost continually over the wash event. The appliance stock survey also provided confirmation that the recorded average flow rate for the clothes washer in this particular home was considerably lower than the other homes in the study. This meant the pump was operating well below its optimum capacity for a long period of time, resulting in large total energy consumption and large energy intensity.

Again, there was a tendency for modern water efficient appliances to have high energy intensities due to them not being properly matched with the optimal pump operating capacity. 


\subsubsection{Irrigation end use category}

The surveys completed by participants indicated that many homes irrigated infrequently (i.e. car washing, garden watering, pool filling), but it was still expected that 20 events could be captured for most homes, given the long 6 month collection period. However, during the first 4 months of the data collection period, Gold Coast City experienced $150 \%$ of the average rainfall, while the entire data collection period experienced $128 \%$ of average rainfall [48]. This is thought to have greatly affected the number of irrigation events in many households; which was confirmed through conversations with participants during maintenance visits. In total, 145 irrigation events were collected from 12 households (Table 7). Nonetheless, while there were lesser samples for each household than the other IPRWT supplied end use categories, the data was sufficient to identify the key energy intensity trends for irrigation events.

Due to the user-controlled nature of irrigation events, they varied greatly in terms of duration, volume and flow rate. The standard deviation ranged from $0.03 \mathrm{Wh} / \mathrm{L}$ for RW04 to $0.48 \mathrm{Wh} / \mathrm{L}$ for RW14, with the latter representing the largest end use standard deviation for any home in the study for any end use. Generally irrigation events had high flow rates, which led to this end use having the lowest average intensity (i.e. 1.12 Wh/L). RW04 had a number of high flow rate events leading to an energy intensity of just $0.74 \mathrm{Wh} / \mathrm{L}$. On the other hand, RW28 was the least efficient at $1.66 \mathrm{Wh} / \mathrm{L}$. Interestingly, these systems contain the same 770W pump. This demonstrates that the event flow rate is one of the primary determinants of energy intensity in fixed speed pump systems, with the RW28 events taking on average nearly twice as long as the RW04 events to supply a similar volume of water. Hence, to attain lower energy intensities for the typical pumps supplied in the region, users should be advised to use high flow rate irrigation equipment and/or nozzles. Results for all homes are summarised in Table 7. 
Table 7 Irrigation end use category descriptive data

\begin{tabular}{lcccc}
\hline Home & $\begin{array}{c}\text { Average tank } \\
\text { water } \\
\text { consumption } \\
\text { (L) }\end{array}$ & $\begin{array}{c}\text { Average } \\
\text { electricity } \\
\text { consumption } \\
\text { (Wh) }\end{array}$ & $\begin{array}{c}\text { Average duration } \\
\text { (s) }\end{array}$ & $\begin{array}{c}\text { Average } \\
\text { energy } \\
\text { intensity } \\
\text { (Wh/L) }\end{array}$ \\
\hline RW01 & 225.29 & 227.80 & 1518.75 & 1.01 \\
RW04 & 272.48 & 253.87 & 1547.25 & 0.93 \\
RW07 & 83.75 & 109.47 & 627.50 & 1.31 \\
RW11 & 19.18 & 22.45 & 155.50 & 1.17 \\
RW12 & 400.92 & 334.73 & 1481.75 & 0.83 \\
RW14 & 339.00 & 346.92 & 2404.25 & 1.02 \\
RW18 & 8.25 & 10.31 & 83.50 & 1.25 \\
RW19 & 15.84 & 14.18 & 79.00 & 0.90 \\
RW22 & 4.58 & 4.80 & 33.00 & 1.05 \\
RW24 & 243.47 & 265.13 & 1721.25 & 1.09 \\
RW26 & 25.89 & 30.80 & 252.75 & 1.19 \\
RW28 & 184.05 & 306.22 & 2049.25 & 1.66 \\
\hline Average & 151.89 & 160.56 & 996.15 & 1.12 \\
SD & 143.131 & 140.529 & 875.274 & 0.224 \\
\hline
\end{tabular}

\section{$4 \quad$ End use energy intensity comparative assessment}

\subsection{Comparing energy intensity values}

RWT systems require electricity for the operation of the pump and switch to supply connected end uses. A total of 1,210 different end use events were analysed and categorised into their four different end use categories, namely, half flush toilet, full flush toilet, clothes washer and irrigation. Figure 6 provides a summary of the entire sample average energy intensity, as well as the average electricity and water usage for the four RWT end use event categories. As expected, the highest average energy intensity values were obtained from the half flush toilet category as the RWT pump is required to initiate and stop for a very short period of time, a low cistern fill flow rate and a relatively small volume of water. Irrigation events had the lowest average energy intensity of the four RWT supplied end uses examined in this study. Generally, irrigation events had a long duration and overall volume as well as a higher flow rate that better suited the optimal pump operating level. 

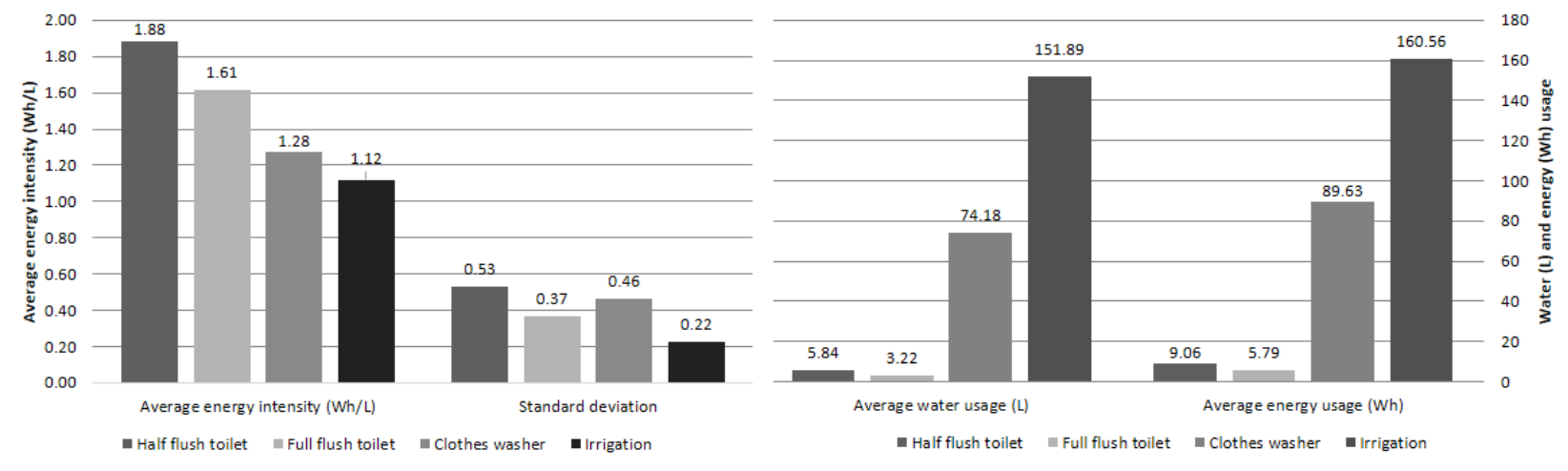

Fig. 6. Average energy intensity, average electricity and water usage for the four end use categories

\subsection{Comparing event water and energy usage and frequencies}

Since the water-energy nexus is complex and multi-faceted, the energy intensity parameter provides only one perspective towards the evaluation of a RWT systems performance. The average and total water and energy consumption of individual events and the household over a period of time should also be considered in order to have the complete picture of their performance and to make informed RWT design refinement decisions (Figure 6). For example, half flush toilet events have the highest average energy intensity but the lowest average water and electricity consumption (i.e. resource usage is only approximately $2 \%$ of the average irrigation event). But as evident below, even though irrigation events have much higher volumes than toilet flush events, their low frequency in most homes mean that this category requires the least amount of energy.

\subsection{Comparing theoretically calculated values of pump energy intensity with actual values}

As discussed previously, there have been a number of studies that have theoretically calculated or conducted field experiments to determine the energy intensity of rain tanks of various configurations. These studies resulted in a wide range of energy intensity values for rain tanks from $0.06 \mathrm{Kwh} / \mathrm{m}^{3}$ [28] to $5.3 \mathrm{kwh} / \mathrm{m} 3$ [27]. Comparison of the theoretical energy intensity values of the rain tanks utilised in the study with the actual collected data is the purpose of this section. To achieve this objective, two equations were utilised for estimating the energy intensity of rain tank systems. The first equation $[50,51]$ is the most fundamental considering only the pump operational energy in terms of the pump power rating and its' operational period while the latter [31] incorporates a range of other factors such as the extra energy required for pump start-up and also stand-by 
energy usage. Dixon [50] and Reobuk [51] formulated two basic theoretical pump energy usage expressions as described in Equations 1 and 2 below:

$$
\begin{aligned}
& E_{T O T}=P_{R} \times O_{D} \\
& O_{D}=\frac{V}{P_{C}}
\end{aligned}
$$

Where, $\mathrm{O}_{\mathrm{D}}$ is the pump operation duration $(\mathrm{h}), \mathrm{P}_{\mathrm{R}}$ is the pump rating $(\mathrm{kW}), \mathrm{V}$ is the volume of the water pumped and $\mathrm{P}_{\mathrm{C}}$ is the pump capacity $\left(\mathrm{m}^{3} / \mathrm{h}\right)$.

Cunio and Sproul [26] used these equations to calculate an energy intensity value range of $0.1-0.2$ $\mathrm{kWh} / \mathrm{m}^{3}$ for their rain tank study. Their low energy intensity values considered the optimal utilisation of the pump system, which is not often the case for residential installations. For instance, a $770 \mathrm{~W}$ pump has an $80 \mathrm{~L} / \mathrm{s}$ pumping capacity but if this pump is more often used for toilet flushing end use events that have very low flow rates (i.e. 0.05-0.1 L/s), their actual efficiency is much lower in reality. Retemal et al. [21] applied this theory to calculate the theoretical energy intensity of homes instrumented in their study and to conduct a comparative assessment. Differently to the Cunio and Sproul [26] study, they inserted the actual input values obtained from their experiments (i.e. actual durations) and calculated higher energy intensity values of $0.9-2.3 \mathrm{kWh} / \mathrm{m}^{3}$. Their results highlighted that the pump rating $\left(\mathrm{P}_{\mathrm{R}}\right)$ becomes much less than the manufacturer specification document due to very low flow rates for many residential end use categories. Specifically, they indicate that the pump and motor efficiency of internally plumbed residential rain tank pump systems was less than $40 \%$ as a result of such low flow rates for filling toilet cisterns, which is well below the $60-70 \%$ pump system efficiency values stated in the pump specifications.

In summary, the key point is that the fundamental pump equations are appropriate when considering higher flow rate pump operations that have longer operational cycles (i.e. similar to distribution system pump cycle to storage reservoir). However, the nature of residential rain tank pump configurations and the often poor match of the pump size for most of the internal end use events means that these fundamental equations do not adequately consider the much lower system efficiency actually achieved due to the numerous start-ups, variable flow rates of different events, standby power, etc. These factors were taken into the account in the most recent theoretical study that was completed by Ward et al. [31]. Their study considered the fundamental equations pump 
operational energy components but also incorporated a number of other factors such as start-up and stand-by energy. This expanded equation essentially scaled up the theoretical estimates of the fundamental equations (Eq. 1 and 2 above) in order to allow for this loss in system efficiency due to these factors related to intermittent operational characteristics of residential rain tanks (Eq. 3).

$$
\begin{aligned}
E_{T O T}=\left[\left(P_{R} \times O_{D S}\right)+\left(P_{R} \times O_{D S} \times S_{F}\right)+\left(P_{R} \times O_{D O}\right)\right] \\
+\left[\left[\left(P_{R} \times O_{D S}\right)+\left(P_{R} \times O_{D S} \times S_{F}\right)+\left(P_{R} \times O_{D O}\right)\right] \times\left(1-\frac{P_{R}}{P_{I}}\right)\right]
\end{aligned}
$$

where $E_{T O T}$ is the total energy consumed in the pumping system (kWh), $P_{R}$ is pump rating $(\mathrm{kW}), \mathrm{O}_{\mathrm{DS}}$ is start-up operation duration $(\mathrm{h}), \mathrm{S}_{\mathrm{F}}$ is start-up energy factor(extra energy used during start-up in relation to constant flow operation), $\mathrm{O}_{\mathrm{DO}}$ is operation duration and $\mathrm{P}_{\mathrm{I}}$ is pump input power $(\mathrm{kW})$.

Given that in this study we are concerned with Energy Intensity (EI) values and not total energy values, $\mathrm{E}_{\mathrm{TOT}}$ values were converted to EI values using Eq. 4 as follows:

$$
E I=\frac{E_{T O T}}{V_{T O T}}
$$

Where EI is the energy intensity of the pump system $\left(\mathrm{kWh} / \mathrm{m}^{3}\right), \mathrm{E}_{\mathrm{TOT}}$ is the total energy consumed in the pumping system $(\mathrm{kWh})$ and $\mathrm{V}_{\text {Tот }}$ is the volume of rainwater pumped $\left(\mathrm{m}^{3}\right)$.

Ward et al. [31] utilised their modified equation to calculate an energy intensity value of0.54 $\mathrm{kWh} / \mathrm{m}^{3}$ for the rainwater tank system used in their study (i.e. University Building). This value was $68 \%$ greater than the $0.32 \mathrm{kWh} / \mathrm{m}^{3}$ value calculated using Eq. 1 [50].

For the purposes of this study, Eq. 1 and 3 were utilised to calculate the theoretical energy intensity of our water end use categories for the three pump sizes that existed in our study. It should be noted that these equations were not formulated for a bottom-up end use level calculation of pump energy, which was the focus of our current study. For instance, a clothes washer event would have a number of wash cycles. In this case, we would consider each washer cycle as a distinct event and sum all wash cycle estimates to create the total 
estimated energy and water use for that clothes washer event. Table 8 presents a comparative assessment between the two theoretical methods (Eq. 1 and 3) and the actual energy intensity values derived through the field experiment. Input values for the two theoretical equations came from the actual event characteristic information (e.g. duration, etc.). As shown in Table 8, the Ward et al. [31] equation yielded results which were 50-70\% higher than the basic theoretical equation and were much closer to the actual recorded values (i.e. difference range of $-7 \%$ to $26 \%$ of the actual values).

Table 8 Comparison between basic two theoretical equations and field experiment data

\begin{tabular}{|c|c|c|c|c|c|c|c|}
\hline \multirow{2}{*}{\multicolumn{2}{|c|}{$\begin{array}{l}\text { Pump input power / end use } \\
\text { / method) }\end{array}$}} & \multirow{2}{*}{$\begin{array}{c}\begin{array}{c}\text { Dixon [49] } \\
\text { equation }\end{array} \\
\begin{array}{r}\text { Energy intensity } \\
(\mathrm{Wh} / \mathrm{L})\end{array} \\
\end{array}$} & \multicolumn{2}{|c|}{ Ward [31]equation } & \multicolumn{3}{|c|}{ Field experiment data } \\
\hline & & & $\begin{array}{r}\text { Energy } \\
\text { intensity } \\
(\mathrm{Wh} / \mathrm{L})\end{array}$ & $\%$ Increase $^{1}$ & $\begin{array}{r}\text { Energy intensity } \\
(\mathrm{Wh} / \mathrm{L})\end{array}$ & $\%$ increase $^{2}$ & $\%$ difference ${ }^{3}$ \\
\hline \multirow{4}{*}{$\begin{array}{l}720 \mathrm{~W} \\
(\mathrm{~N}=2)\end{array}$} & Half flush cistern & 1.09 & 1.83 & 67.89 & 2.26 & 107.34 & 23.50 \\
\hline & Full flush cistern & 0.87 & 1.45 & 66.67 & 1.83 & 110.34 & 26.21 \\
\hline & Clothes washer & 0.51 & 0.79 & 54.90 & 0.99 & 94.12 & 25.32 \\
\hline & Irrigation & 0.50 & 0.76 & 52.00 & 0.90 & 80.00 & 18.42 \\
\hline \multirow{4}{*}{$\begin{array}{l}770 \mathrm{~W} \\
(\mathrm{~N}=11)\end{array}$} & Half flush cistern & 1.15 & 1.97 & 71.30 & 1.75 & 52.17 & -11.17 \\
\hline & Full flush cistern & 0.91 & 1.56 & 71.43 & 1.55 & 70.33 & -0.64 \\
\hline & Clothes washer & 0.65 & 1.11 & 70.77 & 1.22 & 87.69 & 9.91 \\
\hline & Irrigation & 0.79 & 1.19 & 50.63 & 1.12 & 41.77 & -5.88 \\
\hline \multirow{4}{*}{$\begin{array}{l}1170 \mathrm{~W} \\
(\mathrm{~N}=1)\end{array}$} & Half flush cistern & 1.14 & 2.00 & 75.44 & 1.86 & 63.16 & -7.00 \\
\hline & Full flush cistern & 0.96 & 1.64 & 70.83 & 1.68 & 75.00 & 2.44 \\
\hline & Clothes washer & 0.88 & 1.51 & 71.59 & 1.63 & 85.23 & 7.95 \\
\hline & Irrigation & 0.60 & 0.90 & 50.00 & 0.83 & 38.33 & -7.78 \\
\hline
\end{tabular}

To illustrate these differences, Figure 7 shows a comparison between the two theoretical equations and the actual energy intensity results for the more prevalent 770W pump size utilised in the study region. The Ward et al. [31] equation calculated results very close to the actual values. The only major exception is that it produced a reasonably higher energy intensity value for the half flush end use category. This higher value is due to the Ward et al. [31] considering a higher $S_{F}$ value of 0.6 which was higher than the 0.33 value evident in the real data for this end use category. Overall, the Ward et al. [31] equation was much more appropriate for calculating residential rain tank systems energy intensity values since it better considered the system efficiency issues of these systems.

An important aspect highlighted in this study, was that the current suite of rain tank pumps and the internally plumbed tank configuration often installed by plumbers in Australia is not optimal for the vast 
majority of low flow rate end use events used in typical homes. Where a household is predominately using the pump for toilet flushing and clothes washing activities than a much smaller pump size is recommended (e.g. 200-300 W pump). Cunio and Sproul [26] conducted a small laboratory study and came to the same conclusion.

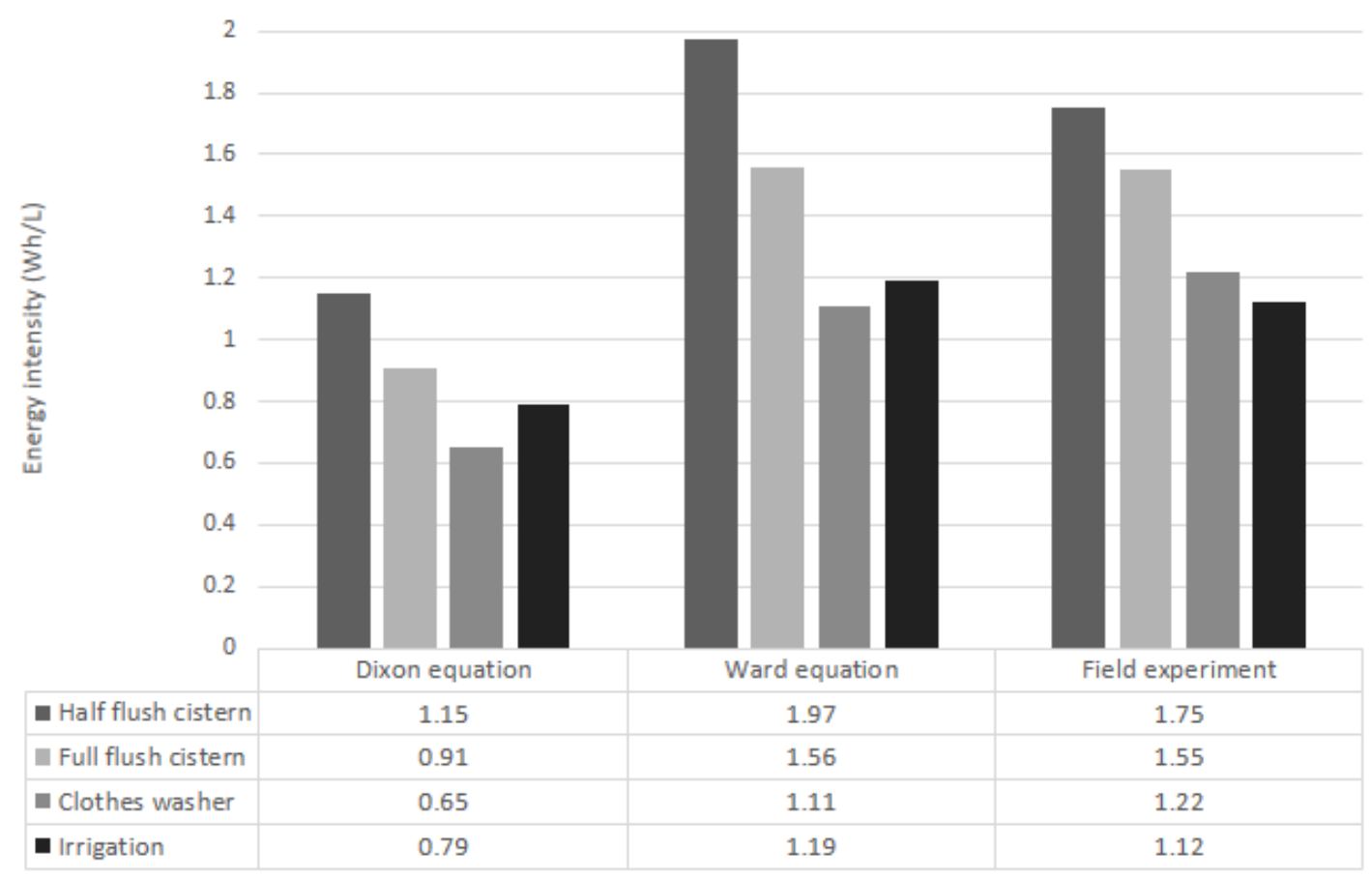

Fig. 7. Comparison between energy intensity values for different end uses for the $770 \mathrm{~W}$ pump

\section{Conclusions, recommendations and future research directions}

\subsection{Conclusions}

Substituting some town water with rain water for suitable end uses can potentially save one third of domestic water demand $[20,46]$. In the recent drought in Australia, IPRWT were seen as viable strategy for reducing potable demand across most of eastern Australia. Although there have been a number of studies examining the performance of RWT systems with respect to potable water savings, there are few covering the energetics of RWT systems, with none internationally conducting a true field experiment that examines RWT pumps energy intensity values at an end use or micro-component level. This present study attempts to fill this critical gap to provide the water and energy consumption values for the four IPRWT supplied end uses as well as their energy intensities. Overall, this study revealed that the predominate installation of IPRWT in Gold Coast City, and 
likely across most of eastern Australia, is inadequate as the fixed speed pumps largely installed are producing unnecessarily high energy intensity values for the internal end uses they predominately supply (i.e. toilet and clothes washer). Toilet and clothes washer water efficiency is improving remarkably and this trend should not be discouraged to suit the present inadequately specified RWT pump installations on most households. Instead, pump design should be matched to suit the flow rates required by these efficient appliances. This could involve using variable speed pumps that can better match the pumps operating level with the events flow rate demand.

\subsection{Recommendations}

The following recommendations have resulted from this study:

- Consider better guidelines for the design of RWT systems with a particular focus on the design of their pumps and switching systems.

- Pump type and sizing should be customised to the household, especially where there are small lots will little or no impervious area for irrigation, implying that most end uses supplied by the RWT pump will be low flow indoor events requiring a lower powered pump. Further research would be required to create a robust rain water tank pump customisation selection tool.

- This study showed that residential water end uses supplied by IPRWT exhibit highly variable flow rates (i.e. very low toilet cistern filling rate to high flow rate irrigation events) that do effectively match the pump curves of popular fixed speed pumps. While variable speeds pumps are often more expensive than fixed speed pumps, they will be more appropriate for application in residential households as they will be able to adapt to the highly variable flow rates prevalent, thus resulting in a lower overall energy intensity for the household.

- Toilet flushing is a considerable water end use supplied by the IPRWT and requires very low flow rates for cistern filling. The energy intensity for the toilet flushing category could be reduced considerably if a small header tank was installed in the buildings' roof cavity (e.g. approx. $2.4 \mathrm{~m}$ head for single storey house). This header tank could be refilled in one daily pump cycle at the pumps optimal flow rate and then gravity fed to refill toilet cisterns.

- Homeowners with IPRWT should consider that high flow rate events typically attract lower energy intensities. This could be taken into consideration when purchasing and using clothes washers, toilet 
cisterns and irrigation equipment. For user controlled flow rate events such as car washing and manual irrigation this should also be taken into account.

- Household water use patterns (e.g. rarely irrigate) and their appliance mechanistic operations (e.g. front load clothes washer cycle features) should be considered when purchasing the type and power rating of a residential pump, as a mismatch between these will lead to an unnecessarily higher energy demand.

\subsection{Research limitations}

While this study included a very detailed experimental program that provided the researchers with a comprehensive dataset for high resolution data mining and analysis it has some limitations as discussed below:

- $\quad$ The sample size was limited to 19 residential properties located in Gold Coast City, Australia. This sample size was restricted by the budget of the research project and the cost of setting up and maintaining the field experiment (i.e. approx. AUD\$4,000 per household for installation alone).

- $\quad$ There were limited available rain tank pump and switch systems on the market that were utilised by plumbers for installation at households in the region and more generally across Australia. Moreover, the plumbing association tended to recommend a certain type of system/design meaning that the majority of new constructed households in the city with IPRWT had similar pump power ratings (i.e. $770 \mathrm{~W}$ ). Ideally, the inclusion of some households with lower power ratings (e.g. 400W) would have provided some evidence to show that these smaller pumps had lower energy intensities than higher wattage pumps for low flow rate events such as cistern filling and front loader washer cycles.

- The data collection period and extent of end use disaggregation analysis was not for the ideal full year period with a normal rainfall pattern. Data collection for this project was from three data loggers sending via GPRS four channels of high resolution water and energy data every five seconds. As expected, such a study produced considerable datasets for analysis. The project scope did not have a budget to manually disaggregate all collected data into each and every end use event supplied by the IPRWT over a full year along with its energy requirements. To conduct such extensive flow and energy disaggregation analysis would have taken many thousands of researcher hours, which was outside the study budget and scope. Instead, a representative sample of 20 events for each end use category was analysed and secondary data from aligned water end use studies in the region was used to create frequencies of use that could be inserted into a rain tank yield modelling software package. This process enabled the energy intensity values and also the total energy and water to be determined. In summary, ideally each and every end use event for all homes were analysed over a typical rainfall year for the project to determine these values, but this was not feasible with limited resource capacity.

\subsection{Future research directions}

Future research seeks to data mine the determinants and predictors of energy intensity for the four examined water end use events (i.e. half flush and full flush toilet, clothes washer and irrigation). This study will further 
explore relationships between pump models and sizes, RWT-supplied water appliance efficiency, pipe losses (i.e. distance between pump and appliance) and household demographics, and the dependent variable energy intensity for each end use category. Moreover, based on this analysis, a series of prediction functions will be developed as well as a user-friendly RWT pump design tool in order to better configure RWT pumps to household characteristics (i.e. appliances, demographics, water usage patterns, etc.). Such efforts should help to lower the energy required to substitute potable water with rain water across urban areas, not only in Australia but internationally.

\section{Acknowledgement}

The study was funded by an Australian Research Council (ARC) Linkage Project that also includes funding from our core industry partner Gold Coast City Council. The University of Technology (UTS), Sydney and CSIRO are also partnered investigators to this grant. Special thanks to Griffith eResearch Services Team for developing and supporting the Smart Meter Information Portal, and Dr Ruby Gonzales at Griffith University for establishing an FTP server. Finally, the authors greatly appreciate the kind support of the households involved in the study.

\section{References}

[1] R. Malik, Water-energy nexus in resource-poor economies: the Indian experience, Water Resources Development, 18 (1) (2002) 47-58.

[2] C. Cheng, Study of the inter-relationship between water use and energy conservation for a building, Energy Buildings, 34 (3) (2002) 261-266.

[3] S. Kenway, A. Preistly, S. Cook, S. Seo, M. Inman, A. Gregory, Energy use in the provision and consumption of urban water in Australia and New Zealand, in: Water for a Healthy Country National Research Flagship, CSIRO, 2008.

[4] C. Liedl, W. Lubitz, Comparing domestic water heating technologies, Technol Soc, 31 (3) (2009) 244256.

[5] J.S. Weihl, W. Kempton, Residential hot water energy analysis: Instruments and algorithms, Energy Buildings, 8 (7) (1985) 197-204.

[6] R.M. Willis, R.A. Stewart, K. Panuwatwanich, S. Jones, A. Kyriakides, Alarming visual display monitors affecting shower end use water and energy conservation in Australian residential households, Resources, Conservation and Recycling, 54 (12) (2010) 1117-1127.

[7] C. Beal, E. Bertone, R.A. Stewart, Evaluating the energy and carbon reductions resulting from resourceefficient household stock, Energ Buildings, 55 (December) (2012) 422-432.

[8] O. Dahlstrøm, K. Sørnes, S.T. Eriksend, E.G. Hertwich, Life cycle assessment of a single-family residence built to either conventional- or passive house standard, Energy Buildings, 54 (November) (2012) 470-479.

[9] R. Siems, O. Sahin, M.R Talebpour, R. Stewart, M. Hopewell, Energy intensity of decentralised water supply systems utilised in addressing water shortages, in: 8th International Conference of the European Water Resources Association, Porto, Portugal, 2013. 
[10] T. Herrmann, U. Schmida, Rainwater utilisation in Germany: efficiency, dimensioning, hydraulic and environmental aspects, Urban Water, 1 (4) (2000) 307-316.

[11] M. Retamal, K. Abeysuriya, A. Turner, S. White, Water Energy Nexus: Literature Review, in, Institute for Sustainable Futures, University of Technology, Sydney, 2008.

[12] L.C. Proenca, E. Ghisi, D.d. Tavares, G.M. Coelho, Potential for electricity savings by reducing potable water consumption in a city scale, Resour Conserv Recy, 55 (11) (2011) 960-965.

[13] D. Whittington, S.K. Pattanayak, J. Yang, K.C. Bal-Kumar, Household demand for improved piped water services: evidence from Kathmandu, Nepal, Water Policy, 4 (6) (2002) 531-556.

[14] S. Umapathi, M.N. Chong, A.K. Sharma, Evaluation of plumbed rainwater tanks in households for sustainable water resource management: A real-time monitoring study, J Clean Prod, 42 (March) (2013) 204-214.

[15] K.W. König, D. Sperfeld, Rainwater Harvesting - A global issue matures, in, Association for Rainwater Harvesting and Water Utilisation, Darmstadt, Germany, 2006.

[16] Queensland Government, Queensland Development Code Mandatory Part 4.2 - Water Savings Targets, in, Department of Housing and Public Works, 2007.

[17] Environment Agency, Harvesting rainwater for domestic uses: an information guide, in, United Kingdom, 2010.

[18] M.N. Chong, S. Umapathi, A. Mankad, T. Gardner, A.K. Sharma, S. Biermann, Estimating water savings from mandated rainwater tanks in south east Queensland, in: 3rd Urban Water Security Research Alliance Science Forum, Brisbane, QLD, 14-15 September, 2011, pp. 31-34.

[19] P. Coombes, G. Kuczera, J. Kalma, Economic, water quantity and quality impacts from the use of a rainwater tank in the inner city, Australian Journal of Water Resources, 7 (2) (2003) 111-120.

[20] C.D. Beal, A. Sharma, T. Gardner, M. Chong, A Desktop Analysis of Potable Water Savings from Internally Plumbed Rainwater Tanks in South-East Queensland, Australia, Water Resources Management, 26 (6) (2012) 1577-1590.

[21] M. Retamal, J. Glassmire, K. Abeysuriya, A. Turner, S. White, The Water-Energy Nexus: Investigation into the Energy Implications of Household Rainwater Systems, in, Institute for Sustainable Futures, University of Technology, Sydney, 2009.

[22] C. Beal, B. Hood, T. Gardner, C. Christiansen, J. Lane, Energy and water metabolism of a sustainable subdivision in South East Queensland: a reality check, Enviro ${ }^{\text {ee }} 08$, Melbourne Exhibition and Convention Centre, AWA, Melbourne, Australia, p. 1-17, 2008

[23] MA. Ferguson 12-month rainwater tank water savings and energy use study for 52 real life installations. Ozwater '12 Conference, 8 - 10 May, Sydney, Australia: 2012.

[24] B. Hood, E. Gardner, R. Barton , R. Gardiner, C. Beal, R. Hyde, Decentralised development: the Ecovillage at Currumbin, Water ;37:37-43, 2010.

[25] M.R. Talebpour, R. Stewart, C. Beal, B. Dowling, A. Sharma, S. Fane, Rainwater Tank End Usage and Energy Demand: A Pilot Study, Water: Journal of the Australian Water Association, 38 (1) (2011) 97101.

[26] L.N. Cunio, A.B. Sproul, Low Energy Pumping Systems for Rainwater Tanks, in: Solar09, the 47th ANZES Annual Conference, Townsville, 2009.

[27] G. Tjandraatmadja, C. Pollard, A. Sharma, T, Gardner. Dissecting rainwater pump energy use in urban households, Science Forum and Stakeholder Engagement: Building Linkages, Collaboration and Science Quality, Brisbane, Australia, 2011.

[28] Y. Chiu, C. Liaw, L. Chen, Optimising rainwater harvesting systems as an innovative approach to saving energy in hilly communities, Renew Energ, 34 (3) (2009) 492-498.

[29] M. Hallman, T. Grant, N. Alsop, Life Cycle Assessment and Life Cycle Costing of Water Tanks as a Supplement to Mains Water Supply, in, Centre for Design at RMIT University, Melbourne, 2003.

[30] E. Ghisi, D.F. Ferreira, Potential for potable water savings by using rainwater and greywater in a multistorey residential building in southern Brazil, Build Environ, 42 (7) (2007) 2512-2522. 
[31] S. Ward, D. Butler, F. Memon, Benchmarking energy consumption and CO2 emissions from rainwaterharvesting systems: an improved method by proxy, Water and Environment Journal, 26. (2012) 184-190.

[32] R.A. Stewart, R. Willis, D. Giurco, K. Panuwatwanich, G. Capati, Web-based knowledge management system: linking smart metering to the future of urban water planning, Australian Planner, 47 (2) (2010) $66-74$.

[33] R.M. Willis, R.A. Stewart, D.P. Giurco, M.R. Talebpour, A. Mousavinejad, End use water consumption in households: impact of socio-demographic factors and efficient devices, J Clean Prod, 66 (December) (2013) 107-115.

[34] C. Beal, R.A. Stewart, K. Fielding, A novel mixed method smart metering approach to reconciling differences between perceived and actual residential end use water consumption, J Clean Prod, 60 (December) (2013) 116-128.

[35] K.A. Nguyen, R.A. Stewart, H. Zhang, An autonomous and intelligent expert system for residential water end-use classification, Expert Systems with Applications, 41 (2) (2013) 342-356.

[36] K.A. Nguyen, R.A. Stewart, H. Zhang, Development of an intelligent model to categorise the residential water end use, Journal of Hydro-Environment Research, 7 (3) (2013) 182-201.

[37] P. Mayer, W. DeOreo, E. Towler, L. Martien, D. Lewis, Tampa Water Department residential water conservation study: the impacts of high efficiency plumbing fixture retrofits in single-family homes. , in, Aquacraft, Inc. Water Engineering and Management, Boulder, Colorado, USA, 2004.

[38] P. Roberts, Yarra Valley Water 2004 residential end use measurement study, in, Yarra Valley Water, Victoria, Australia, 2005.

[39] A. Makki, R.A. Stewart, K. Panuwatwanich, C. Beal, Revealing the determinants of shower water end use consumption: enabling better targeted urban water conservation strategies, J Clean Prod, 60 (December) (2013) 129-146.

[40] C. Beal, R.A. Stewart, Identifying residential water end uses underpinning peak day and hour demand, ASCE Journal of Water Resources Planning and Management, 10.1061/(ASCE)WR.1943-5452.0000357 (Feb. 9, 2013)..

[41] B. Carragher, R.A. Stewart, C. Beal, Quantifying the influence of residential water appliance efficiency on daily diurnal demand patterns at an end use level: a precursor to optimised water service infrastructure planning, Resour Conserv Recy, 62 (2012) 81-90.

[42] R.M. Willis, R.A. Stewart, P.R. Williams, C.H. Hacker, S.C. Emmonds, G. Capati, Residential potable and recycled water end uses in a dual reticulated supply system, Desalination, 272 (1-3) (2011) 201-211.

[43] Gold Coast City Council, Population and Dwelling Profile, in, Office of Economic and Statistical Research, Queensland Treasury and Trade, 2012.

[44] MathWorks, MATLAB, in, Natick, Massachusetts, U.S.A, 2012.

[45] Aquacraft, Trace Wizard, in, Boulder, Colorado, 1997.

[46] R. Stewart, Verifying the end use potable water savings from contemporary residential water supply schemes, in, National Water Commission Waterlines Report No. 61, Australian Government, Canberra, 2011.

[47] R. Willis, R.A. Stewart, K. Panuwatwanich, B. Capati, D. Giurco, Gold Coast domestic water end use study, Water 36 (6) (2009) 79-85.

[48] M. Hoang, B. Bolto, C. Haskard, O. Barron, S. Gray, G. Leslie, Desalination in Australia, in: Water for a Healthy Country Flagship Report series ISSN: 1835-095X, CSIRO, Clayton, Victoria, 2009.

[49] Australian Bureau of Meteorology, Climate Data Online, in, Canberra, Australia, 2013.

[50] A. Dixon, Simulation of Domestic Water Re-Use Systems: Greywater and Rainwater in Combination, Unpublished PhD Thesis, Imperial College, London, 2000.

[51] R. Roebuck, A whole life costing approach for rainwater harvesting systems, Unpublished PhD Thesis, University of Bradford, 2008. 